\title{
Effects of Collaborative Learning Styles on Performance of Students in a Ubiquitous Collaborative Mobile Learning Environment
}

\author{
Michael Ayodele Fakomogbon \\ University of Ilorin, Nigeria \\ Hameed Olalekan Bolaji \\ Al-Hikmah University, Nigeria
}

\begin{abstract}
Collaborative learning is an approach employed by instructors to facilitate learning and improve learner's performance. Mobile learning can accommodate a variety of learning approaches. This study, therefore, investigated the effects of collaborative learning styles on performance of students in a mobile learning environment. The specific purposes of this study are to: examine the difference in the performance of students in mobile learning platform; examine the difference in performance of students in the five collaborative learning styles; examine the significant difference in performance between collaborative and non-collaborative learning styles; and determine the effect of collaborative learning style on student's performance in a mobile learning platform. Purposive sampling technique was used to choose 36 secondary school students as the sample. The study adopted a pretest-posttest experimental approach and subjects were randomly assigned into the five collaborative and one non-collaborative learning group. The groups were exposed to mobile learning on the mole concept (MLMC) in Chemistry. The results showed that there was significant gains regarding the difference between pretest and posttest scores of students in the mobile learning experience, and think-aloud-pair problem-solving technique is the most effective collaborative learning style. Also, all the collaborative learning styles are more effective for learning in a mobile learning environment compared to non-collaborative learning style.
\end{abstract}

Keywords: Collaborative learning; Mobile learning; Ubiquitous learning; Academic performance; Mole concept

\section{Introduction}

The term m-learning is short for mobile learning. It basically means electronic learning through a mobile device, such as mp3 player (iPod), smart cellphone portable computer, or iPad. This means that learners do not have to be in a fixed, predetermined location. A popular definition of mobile learning is education that involves the use of mobile devices to enable learning anytime and anywhere as indicated in a UNESCO (United Nations Education Social and Cultural Organization) report (Vosloo, 2012). This definition captures much of the essence of mobile learning but discussions on mobile learning should focus more on mobility and its unique affordances than on technology per se with questions on how mobile devices can support not only learning but also the broad objectives of educational goals. 
Mobile learning relies on a device with anywhere, anytime wireless access and that it is based on the following concepts as put forward by Rosen (2010); information is available anywhere there is internet access, information is available anytime, information is available through devices that are becoming common place and will soon be affordable to most people, information can be pushed from the environment to the learners and pulled by the learners from the environment and the learning environment is fluid and adapts as the learner learns. The ability to extend educational experiences beyond classrooms and enable non-formal and informal learning can be seen as a key attribute of mobile learning and as well carries enormous potential to make learning more personalized and relevant. However, in this context, mobility could be translated to mean a chance to overcome physical constraints by having access to people and digital learning resources regardless of place and time (Kukulska-Hulme, 2010). Thus, mobile learning can happen in the classroom as well.

Mobile learning is an extension of e-learning and has the potential to make learning even more widely available and accessible than we are used to in existing e-learning environments (Keegan, 2005). The role that communication and interaction plays in the learning process could be termed as a critical success factor. It is within this context that mobile learning can contribute to the quality of education. It can encourage opportunities for the optimization of interaction between lecturers and learners, among learners and among members of a certain group. Vosloo (2012) identified that wireless and mobile technologies also make it possible to provide learning opportunities for learners that do not have access to infrastructure or for those that are continually on the move in their day-to-day activities. Mobile learning through the use of wireless mobile technology allows anyone to access information and learning materials from anywhere and at any time (Ally, 2009).

It is often claimed that Mobile learning, through the use of mobile technology, will allow citizens of the world to access learning materials and information from anywhere and at anytime. This implies that intending learners could look beyond the barriers of time to learn or go to a certain place to learn. Mobile learning can afford the learners the selective option of learning whenever and wherever they want. They can use the wireless mobile technology for formal and informal learning where they can access additional and personalized learning materials from the internet or from the host organization. Looking at mobile learning in a wider context, we have to recognize that mobile, personal, and wireless devices are now radically transforming societal notions of discourse and knowledge which are responsible for new forms of art, employment, language, commerce, deprivation, and crime, as well as learning (Traxler, 2009). With increased popular access to information and knowledge anywhere and anytime around the globe, the role of education, perhaps especially formal education, is challenged and the relationships between education, society, and technology are now more dynamic than ever.

Koole (2009) asserted that mobile learning offer learners a greater access to relevant information, reduced cognitive load and increased access to other people and systems. Wagner (2005) claimed that mobile learning is on the increase as evidenced by the widespread adoption in North American society of mobile wireless technology such as cell phones, personal digital assistants (PDAs), laptop computers, and MP3 players, is irrefutable. Current mobile technologies (especially wireless-frequently referred to as third generation $\{3 G\}$ ) - provide an unprecedented opportunity for inexpensive and beneficial computing power for learners (Wagner, 2005). Mobile learning was defined by Keegan (2005) as the term which simply make provision of education and training on PDAs, palmtops, handhelds, smart phones and mobile phones possible. 
Mobile learning has been defined as any activity that allows individuals to be more productive when consuming, interacting with, or creating information, mediated through a compact digital device that the individual carries on a regular basis, has reliable connectivity and fits in a pocket or purse (eLearning Guild, 2007). As noted in the above definitions, mobile learning could be thought of as being associated with a mobile device that is connected to the internet. Mobile learning relies on a device with anywhere, anytime wireless access and that it is based on these concepts (Rosen, 2010).

It was further highlighted that the following explains the inherent concept of mobile learning: information is available anywhere there is internet access, information is available anytime, instructional design mobile learning information is available through devices that are becoming common place and will soon be affordable to most people. In this regard, information can be pushed from the environment to the learners and pulled by the learners from the environment. The learning environment is fluid and adapts as the learner learn (eLearning Guild, 2007). Mobile learning was first intended to deliver formal learning, such as sideshows or information; but with the rise of blogging and microblogging applications (such as Twitter or Yammer), it is now largely thought as an aid to informal learning (Pachler, Bachmair \& Cook, 2009). That is, rather than delivering full courses, mobile learning is more about performance support and complimenting teaching (Clark, 2011).

Mobile learning is learning using wireless devices that can be used wherever the learner's device can receive unbroken transmission signals and the mobile devices include not only smart phones but also devices like mobile tablets and personal digital aids (Fuxin, 2012). The definition for mobile learning contains three key components - mobility of technology, mobility of learners and mobility of learning processes as highlighted by Fuxin (2012). Mobility of technology refers to the mobile nature of installed hardware and software that enable constant wireless internet connection. Mobility of learners means learners are no longer physically attached to one or several learning sites and they can be mobile and learn at the same time as long as the mobile devices are around. Finally, mobility of learning is the result of mobility of both the technology and learners (Cronje \& El-Hussein, 2010).

Generally, research on mobile learning can be grouped into the following categories; games and competition in learning, classroom learning, laboratories learning, field trip learning, distance learning, informal learning, pedagogical and learning theory, learning and teaching support, mobile learning architecture, and mobile evaluation, requirements, and human interface (Goh \& Kinshuk, 2006). Classroom learning could explore the use of mobile devices in the laboratory environment to support individual learning as well as collaborative learning. The major difference between mobile learning and traditional classroom lecture form of learning is that the former is learner-centered as opposed to classroom lecture form of learning which is teacher-centered. The traditional forms of learning could require learners to be present in one fixed location, whereas, with mobile learning, students can be anywhere as long as there is access to internet connectivity.

Mobile phones solve this problem and promote learning anytime and everywhere (Cronje \& ElHussein, 2010). By this assertion, mobile learning could present an opportunity where learners will be privileged to achieve learning via the use of smart or hand-held phones which they might consider as a great advantage. Mobile learning is a conscious effort made in delivering learning content and experiences to learners when and where they need it. Typically, mobile learning is accessed via a mobile device that facilitates just-in-time learning and on-demand learning. 
Mobile learning can be formal or informal, structured or unstructured, flexible, self-paced and self-directed which is driven by the learner rather than the technology learners use to access it (Turner, 2012). He further stated that mobile learning is supported by a variety of mobile devices and technologies that facilitate the delivery of documents, presentations, multimedia, notifications, news, assignments, quizzes and educational courseware that can all contribute to m-learning. These includes smart phones (e.g. iPhone), laptops, tablets (e.g. iPad), PDA (personal digital assistant), iPod, gaming devices and so on.

Mobile learning can be termed the ability to access educational resources, tools and materials at anytime from anywhere, using a mobile device. Mobile devices are primarily communication tools and many PDAs now offer several communication protocols such as GPRS and/or Wi-Fi. This connectivity can supports synchronous communication using voice, voice over internet protocol (VOIP) or instant messaging as well as asynchronous communication via email, weblogs, web forums, wikis, and virtual learning environments. In recent years, researchers have investigated the potential of mobile handheld devices to support collaborative learning by devising educational scenarios that makes use of collaborative, interactive, and mobile capabilities (Clough, Jones, MacAndrew \& Scanlon, 2009). The advancements in technological computing and wireless communication combined with rapid adoption of sophisticated mobile multimedia devices and applications have created new software tools for people to connect and interact; therefore changing the ways we communicate and collaborate (Liu \& Milrad, 2010). The usage of hand-held devices contributes to the creation of new patterns of interaction and classroom dynamics that may support learning in many ways: they connect the classroom to the outside world, facilitate social learning process and contextualize the learning experience (Liu, Tao \& Nee, 2008; Vavoula, Sharples, Rudman, Meek \& Lonsdale, 2009; Vogel, Spikol, Kurti \& Milrad, 2010). PDAs have been introduced into schools, both inside the classroom (DiGiano, Yarnall, Patton, Roschelle, Tatar \& Manley, 2003) and outside the classroom in support of fieldwork (Chen, Kao \& Sheu, 2003). Research has also been conducted in the wider learning sphere, with the use of handhelds as interactive museum guidebooks (Hsi, 2003) and as tools to support medical students on hospital placements (Smordal \& Gregory, 2003).

Roschelle (2003) identified two distinct forms of collaborative participation: the normal social participation in classroom discussion and the new informatics participation among connected devices. He discovered that in the classroom setting, where the learners were in the same physical space, the normal face-to-face social interaction was supplemented by the wireless interaction between the connected devices. In this context, mobile devices added a new social dimension of participation that was not otherwise available (Clough, Jones, MacAndrew \& Scanlon, 2009). Collaborative learning by definition is a situation in which two or more people learn or attempt to learn something together (Chatti, Hamdan \& Schaper, 2012). In other words, collaborative learning could be categorize as one form of social interaction during learning processes that provides an additional platform for coordination within formal and informal learning environments. According to Chatti, Hamdan \& Schaper (2012), three major elements are inherent in collaborative learning which includes scales of participation, learning context and methods of collaboration. Scale of participation deals with the size of the participant which might be either in a pair, a small group, a class, or a society and the collaboration time span. Learning contexts element in collaborative learning could be within a formal context (e.g. sharing course material) or through joint problem solving where learning is a side effect measured by the improved performance of problem solving or gained knowledge. The methods of collaboration can range from asynchronous communication to synchronous or co-location collaboration and this can trigger activities such as explanation, disagreement and mutual regulation. 
Grouping students for collaborative learning allows them to share their ideas and learning experiences, and further promotes the learning performance of the group as well as of the individuals (Huang, Wu \& Chen, 2012; Wang \& Hwang, 2012). It is further indicated by AdanCoello, Tobar, Faria, Menezes, and Freitas (2011) that group members' learning styles might affect peer interactions in collaborative learning activities. According to Laal and Laal (2012), collaborative learning $(\mathrm{CL})$ is an educational approach to teaching and learning that involves groups of learners working together to solve a problem, complete a task, or create a product. It is also based upon consensus building through cooperation by group members, in contrast to competition in which individuals best other group members.

Meanwhile, from the conceptual definitions given above, mobile learning could be termed the union of mobile technology garnished with e-learning and three major components are synonymous with a mobile learning environment namely mobile devices, wireless technology and students/instructors (Chatti, Hamdan \& Schaper, 2012). The theory of mobile learning examines how learning flows across locations, topics, times, and technologies (Reis, Bonacin \& Martins, 2009). Context is a central construct of mobile learning raising a fundamental challenge on how to enable meaning making from the flow of everyday activity. Mobile learning is a new process of learning through exploration and conversation across multiple contexts amongst people and interactive technologies (Arnedello-Sanchez et al., 2009).

Mobile learning becomes interactive when used in a collaborative environment (Chatti et al., 2012). The importance of collaborative learning in both formal and informal learning could be associated to the interaction and exchange of information. Collaborative learning through mobile devices has been investigated mainly because of the availability and mobility offered by these devices (Spikol, 2008). According to Jain, Birholtz, Cutrell and Balakrishnan (2011), collaborative mobile learning is an activity that allows transparent collaboration by empowering the social negotiation space of group members, coordination between the activity states, encouraging members' mobility, possibility of mediation in interactivity, organization of the managed material and enabling students to collaborate in groups through wireless network supporting social face-to-face communication.

Collaboration is also entertaining, as it integrates a variety of mediums like video clips, instant messages, photos, music, simulations and animations which are exchanged during collaborative mobile learning sessions (Kopler, 2009). One major perspective posited by Reis, Bonacin and Martins (2009) is enriching the mobile environment with multimedia resources like video, audio, images, simulations and animations. With the use of multimedia inputs, users can employ artefact to explain their point of view quickly and easily in a context of collaborative learning.

From all the literature reviewed in this sub-heading, it can be concluded that mobile learning creates an opportunity for students to learn at anytime and anywhere at their convenience. But learning anywhere and anytime requires some basic attributes that could actually present the chances of learning within and outside the classroom environment. The basic features necessary to cause learning in the aforementioned medium are access to portable technologies, stable internet possibilities, technology enhanced with multimedia facilities and quality chunks of instructional contents. The additional option for learning within the confine mobility is collaborative means of sharing and discussing ideas. Mobile learning could support collaborative learning through the share of knowledge, group discussions, group task assignments and all other forms of pervading knowledge gain among collaborating members. Collaborative mobile learning through portable devices or smart phone could arouse, increase, motivate and sustain 
learner's interest toward understanding a difficult concept in a subject area. The collaboration also provides a medium of exchange of personal information and other related attributes of participating members in an online group endeavor.

Well-structured chunks of instructional contents transmitted through a mobile platform, enhanced with audio, video, simulation and animations can a difficult concept more clearly understood by the learners. The different media mix in a mobile learning instructional content may create a meaningful engagement of the learner's intellectual capacity through active involvement in a collaborative learning setting. The availability and accessibility of social network applications also promote individual contribution to a group task in a mobile learning endeavor, hence, initiating long term relationship in the area of discipline and profession interest among participating members in a collaborative environment. It should however be noted that the effectiveness of collaboration in mobile learning could be improved via instructor's approach, quality of instructional content, specification of group dynamism and the appropriate links of multimedia tools to corresponding activity and task.

\section{Research Questions}

The main purpose of this study is to determine the effect of collaborative learning styles on the performance of students in a ubiquitous collaborative mobile learning environment. Therefore, the following specific research questions were stated:

1. What is the difference between pretest and posttest mean scores of students in the mobile learning platform?

2. What is the difference among posttest mean scores of students in the five collaborative learning style groups in the mobile learning platform?

3. Is there any significant difference in performance between students in collaborative and non-collaborative learning styles?

4. What is the effect of collaborative learning style on students' performance in the mobile learning platform?

\section{Research Hypotheses}

$\mathrm{H}_{01}$ : There is no significant difference between the performances of students with collaborative and non-collaborative learning styles in the mobile learning platform.

$\mathrm{Ho}_{2}$ : There is no significant difference in the performances of the students with five collaborative learning styles in the mobile learning platform.

\section{Methodology}

The study is a one group pretest-posttest design-based experimental research. The experiment comprises of six distinct groups with the five of it being collaborative and one being noncollaborative in learning style. All the groups were exposed to treatment (i.e. mobile learning instructional content). The six groups are think-pair-share (TPS), reciprocal teaching (RT), thinkaloud pair problem solving (TAPPS), group grid (GG), group writing assignment (GWA) for 
collaborative learning style and non-collaborative (NC). Each group comprises of six students. The group size of six was determined by the researcher through literature suggestions that group of four or five members work best in a collaborative learning approach while larger groups decrease each member's opportunity to participate actively (CTE-Lilly Teaching Fellows, 2012). Because the literature on these collaborative techniques and styles are common and known, they were not described in details here.

Purposive sampling technique was adopted to select the respondents; major concern was appropriateness of them for the present study. The sample consisted of 36 (18 male, 18 female) Senior Secondary School II (SSS 2) students of Chemistry. They were selected because the class level was not preparing them for any national examination.

Two instruments was employed to examine the performance of the selected sample, namely treatment material and performance test. The treatment instrument was the instructional content on mole concept in Chemistry, designed for mobile learning environment. The test instrument was made up of the pretest and posttest, which was prepared for this particular study.

The subjects were randomly assigned to each of the groups upon completing the online registration in the mobile learning of mole concept (MLMC) database designed and developed by the researcher. The pretest and posttest scores were downloaded from the MLMC administrator's window environment and were subjected to analysis. All the groups were pretested and posttested to measure change in performance.

Research questions were answered based upon descriptive statistics such as means and standard deviations, while hypotheses one and two were tested using t-test and multivariate analysis of variance (MANOVA) respectively.

\section{Findings}

The data collected through the specially-developed instruments were analyzed through proper statistical techniques. Their outcomes are mentioned in relevant tables and interpreted right after each table. It was paid particular attention to present the findings in accordance with either research questions of consequent hypotheses.

Research Question 1: What is the difference between pretest and posttest mean scores of students in the mobile learning platform?

Table 1. Mean Gain and Standard Deviation of Pretest and Posttest Scores

\begin{tabular}{llllll}
\hline & N & Min. & Max. & Mean & SD \\
\hline Pretest & 36 & 1.00 & 8.00 & 5.11 & 1.75 \\
Posttest & 36 & 6.00 & 16.00 & 10.31 & 2.48 \\
\hline
\end{tabular}


The mean gain (5.19) between the pretest and posttest showed that learning of the mole concept through the mobile phone contributed to the improved performance of the students. Therefore, it is possible to conclude that the mobile learning experience in this study has a positive effect on learning pattern of the students.

Research Question 2: What is the difference among posttest mean scores of students in the five collaborative learning style groups in the mobile learning platform?

Table 2. Computation of Posttest Mean Scores among the Collaborative Learning Style

\begin{tabular}{llll}
\hline Group & $\mathbf{N}$ & Mean & St.Dev. \\
\hline TPS & 6 & 11.6667 & 0.81650 \\
TAPPS & 6 & 14.1667 & 1.16905 \\
RT & 6 & 9.6667 & 0.51640 \\
GG & 6 & 8.5000 & 0.83666 \\
GWA & 6 & 10.6667 & 1.75119 \\
\hline
\end{tabular}

Table 2 revealed that the Think-Aloud Pair Problem-Solving (TAPPS) collaborative learning style has the highest posttest mean score $(M=14.17)$, when compared with Think-Pair Share ( $M=11.67)$, Group Writing Assignment ( $M=10.67)$, Reciprocal Teaching ( $M=9.67)$ and Group Grid $(M=8.50)$. This implied that there is a significant difference in the posttest mean scores among the collaborative learning style groups.

$\mathrm{H}_{01}$ : There is no significant difference between performances of the students with collaborative and non-collaborative learning styles in the mobile learning platform.

Table 3. t-test Output on the Significant Difference between Collaborative and Noncollaborative Learning Style

\begin{tabular}{lllllllll}
\hline Group & $\mathbf{N}$ & $\mathbf{M}$ & $\mathbf{S D}$ & $\mathbf{M D}$ & $\mathbf{t}$ & $\mathbf{d f}$ & $\mathbf{p}$ & Decision \\
\hline Collaborative & 30 & 10.93 & 2.21 & 3.77 & 7.42 & 34 & .000 & Reject \\
Non-collaborative & 6 & 7.17 & .75 & 3.77 & & & & \\
\hline
\end{tabular}

In Table 3, the result of the t-test analysis showed that there is a significant difference between performance of the collaborative and non-collaborative learning style in the mobile learning of the mole concept. By implication, $[t(34)=7.42 ; \mathrm{sig}=.000$ and $p<.005]$, the hypothesis is rejected because there is a significant difference between performance of the collaborative and noncollaborative learning style. By extension, the mean difference is 3.77 at a confidence level of $95 \%$. The mean score (10.93) for the collaborative learning style differ significantly from the mean score (7.17) of the non-collaborative learning style, which implies that the collaborative learning style groups performed well above their counterparts in the non-collaborative learning style group of the mobile learning of the mole concept. 
$\mathrm{Ho}_{2}: \quad$ There is no significant difference in the performances of the students with five collaborative learning styles in the mobile learning platform.

Table 4. Multivariate Analysis of Variance on the Five Collaborative Learning Style

\begin{tabular}{|c|c|c|c|c|c|c|c|c|}
\hline Effect & & Value & $\mathbf{F}$ & $\begin{array}{l}\text { Hypothesis } \\
\text { df }\end{array}$ & $\begin{array}{l}\text { Error } \\
\text { df }\end{array}$ & Sig. & $\begin{array}{l}\text { Noncent. } \\
\text { Parameter }\end{array}$ & $\begin{array}{l}\text { Observed } \\
\text { Power }\end{array}$ \\
\hline & Pillai's Trace & .958 & 5.511 & 10.000 & 60.000 & .000 & 55.114 & 1.000 \\
\hline & Wilks' Lambda & .136 & $9.913^{b}$ & 10.000 & 58.000 & .000 & 99.128 & $1.000^{\mathrm{b}}$ \\
\hline \multirow[t]{3}{*}{ Group } & Hotelling's & 5.651 & 15.822 & 10.000 & 56.000 & .000 & 158.221 & 1.000 \\
\hline & Trace & & & & & & & \\
\hline & $\begin{array}{l}\text { Roy's Largest } \\
\text { Root }\end{array}$ & 5.526 & $33.157^{c}$ & 5.000 & 30.000 & .000 & 165.785 & $1.000^{c}$ \\
\hline
\end{tabular}

This finding displayed in Table 4 showed that there is a significant difference with regards to performance among the five collaborative learning style groups. They are all significant $(p<.05)$, so it was concluded that group membership did have a significant effect on the posttest scores of all the groups. The corresponding univariate test for the effects of group membership on the pretest and posttest scores is shown in Table 5.

Table 5. Univariate Test of Between-Subjects Effect

\begin{tabular}{cccccccccc}
\hline Source & $\begin{array}{l}\text { Dependent } \\
\text { Variable }\end{array}$ & $\begin{array}{c}\text { Type III } \\
\text { Sum of } \\
\text { Squares }\end{array}$ & df & $\begin{array}{c}\text { Mean } \\
\text { Square }\end{array}$ & F & Sig. & $\begin{array}{c}\text { Noncent. } \\
\text { Parameter }\end{array}$ & $\begin{array}{c}\text { Observed } \\
\text { Power }\end{array}$ \\
\hline Group & Pretest & 12.222 & 5 & 2.444 & .769 & .579 & 3.846 & .238 \\
& Posttest & 182.472 & 5 & 36.494 & 33.010 & .000 & 165.050 & 1.000 \\
\hline
\end{tabular}

The $p$-values showed that group membership had a significant effect on the results of the posttest $[F(p<0.000=33.01) ; X=36.50]$ compared to the pretest $[F(p>0.579=0.77), X=2.44]$. Therefore, the group membership among the collaborative learning style has affected their posttest scores.

\section{Discussion and Recommendations}

This study compared academic performances of the six groups, five being experimental and one being the control group. The students worked under various treatment conditions, depending upon their learning styles. They all completed the researcher-made pretest and the posttest just before and right after the experiment.

It appears that the mobile learning platform improved the performance of the students. Among various groups, Think-aloud pair problem-solving collaborative learning style is more effective than the others. It is also true that collaborative learning style is effective for group and class work assignment in the mobile learning environment. Thus, the results suggest that students should adopt think-aloud pair problem-solving collaborative learning style to solve problems or complete assignments. 
The comparison of the mean of the pretest and posttest scores shows that there is a main gain of 5.19 points connoting that the mobile learning experience contributed to the improved performance of the respondents. This result is consistent with the results of Clark (2011), which stipulated that mobile learning is more effective in supporting performance and complimenting teaching.

Furthermore, there is a significant difference in the comparison of the mean scores among the collaborative learning style groups with think-aloud pair problem-solving having the highest mean score $(M=14.17)$ compared to the others. This result implies that collaborative learning style is an effective means of facilitating learning. Clough, Jones, MacAndrew and Scanlon (2008) supported this assertion by stating that mobile handheld devices support collaborative learning by devising educational scenarios that makes use of collaborative, interactive, and mobile capabilities. This evidence complements that the various collaborative learning styles have a prevailing influence on students' performance. Considering that there is a significant difference between collaborative and non-collaborative learning styles performance, one can conclude that collaborative learning style is more effective when compared to non-collaborative learning style in a mobile learning environment. In the opinion of Chatti, Hamdan and Schaper (2012), collaborative learning style could be within a formal context or joint problem solving where learning is a side effect measured by the improved performance of problem solving or gained knowledge.

Finally, there is a significant difference among the five collaborative learning style groups as shown in the related tables explaining the effect of the group membership on the performance of the students. This result suggests that various collaborative learning styles do not affect student performance in the same way or at the same level. This comes as no surprise when the paramount amount of evidence in the collaborative learning and learning style literatures are considered in the background.

Based upon the results of the present study, it is possible to make some recommendations both for future research and improved practice. The following are some of the

1. Mobile learning platform should be used for instructional delivery in the classroom to improve performance of students.

2. Think-aloud pair problem-solving collaborative learning style should be employed more frequently for improved performance during the mobile learning experience.

3. Collaborative learning style should be considered more often for students during group work and class assignments in the mobile learning environment.

4. Students should be encouraged as much as possible to adopt the think-aloud pair problem-solving collaborative learning style to solve assignments.

\section{References}

Adan-Coello, J. M., Tobar, C. M., Faria E. S. J., Menezes, W. S, \& Freitas, R. L. (2011). Forming groups for collaborative learning of introductory computer programming based on students' programming skills and learning styles. International Journal of Information and Communication Technology Education, 7(4), 34-46. 
Ally, M. (2009). Mobile learning: Transforming the delivery of education and training. Edmonton, AB: Athabasca University Press.

Arnedillo- Sánchez, I., Kukulska-Hulme, A., Milrad, M., Sharples, M., \& Vavoula, G. (2009). Innovation in mobile learning. International Journal of Mobile and Blended Learning, 1(1), 13-35.

Chatti, M. A., Hamdan, N. A., \& Schaper, H. (2012). Collaboration in mobile learning seminar. Proceedings of the Mobile Learning Computer-Supported Learning Research Group Conference (CALRG 2011). The Open University, United Kingdom.

Chen, Y., Kao, T., \& Sheu, J. (2003). A mobile learning system for scaffolding bird watching learning. Journal of Computer Assisted Learning, 19(3), 347-359.

Clark, Q. (2011). Designing mlearning: Tapping into the mobile revolution for organizational performance. San Francisco: Pfeiffer.

Clough, G., Jones, A. C., McAndrew, P., \& Scanlon, E. (2008). Informal learning with PDAs and smartphones. Journal of Computer Assisted Learning, 24(5), 359-371

Cronje, J. C. \& El-Hussein, M. O. M. (2010). Defining mobile learning in the higher education landscape. Educational Technology \& Society, 13(3), 12-21.

DiGiano, C., Yarnall, L., Patton, C, Roschelle, J, Tatar, D \& Manley, M. (2003). Conceptual tools for planning for the wireless classroom. Journal of Computer Assisted Learning, 19(3), 284-297.

eLearning Guild. (2007). 360 mobile learning research reports. Santa Rosa: CA.

Fuxin, A. Y. (2012). Mobile/smart phone use in higher education. Retrieved on 30 June 2017 from http://swdsi.org/swdsi2012/proceedings_2012/papers/Papers/PA144.pdf

Goh, T. \& Kinshuk, (2006). Getting ready for mobile learning -- adaptation perspective. Journal of Educational Multimedia and Hypermedia, 15(2), 175-198.

Hsi, H. (2003). A study of user experiences mediated by nomadic web content in a museum. Journal of Computer Assisted Learning, 19 (3), 308-319.

Huang, H. W., Wu, C. W., \& Chen, N. S. (2012). The effectiveness of using procedural scaffoldings in a paper-plus smartphone collaborative learning context. Computer \& Education, 59(2), 250-259.

Jain, M., Birnholtz, J. Cutrell, E. \& Balakrishnan, R. (2011). Exploring display techniques for mobile collaborative learning in developing regions. Proceedings of the $13^{\text {th }}$ International Conference on Human-Computer Interaction with Mobile Devices and Services. Stockholm: ACM Press.

Keegan, D. (2005). Mobile learning: The next generation of learning. Distance Education International. Retrieved on 15 February 2015 from learning.ericsson.net

Kopler, E. (2009). Augmented learning: Research and design of mobile educational games. Cambridge, MA: The MIT Press.

Koole, M. L. (2009). A model for framing mobile learning. In M. Ally (Ed.), Mobile learning: transforming the delivery of education and training. Athabasca, Canada: Athabasca University Press.

Kukulska-Hulme, A. (2010). Mobile learning as a catalyst for change. Open learning. The Journal of Open and Distance Learning, 25(3), 181-185. 
Laal, M. \& Laal, M. (2012). Collaborative learning: What is it? Procedia - Social and Behavioral Sciences, 31(2012) 491-49

Liu, C.-C. \& Milrad, M. (2010). Guest editorial - one-to-one learning in the mobile and ubiquitous computing age. Educational Technology \& Society, 13(4), 1-3.

Liu, C. C., Tao, S. Y., \& Nee, J. Y. (2008). Bridging the gap between students and computers: supporting activity awareness for network collaborative learning with GSM network. Behaviour and Information Technology, 27(2), 127-137.

Pachler, N., Bachmair, B., \& Cook, J. (2009). Mobile learning: structures, agency, practices. New York: Springer.

Reis, J. C., Bonacin, R. \& Martins, M. C. (2009). Developing informal education through mobilecollaborative learning. Proceeding of the $12^{\text {th }}$ IASTED International Conference on Computers and Advanced Technology in Education (CATE'09) (pp.1-7). St. Thomas, US Virgin Islands.

Rosen, L. D. (2010). Understanding the igeneration and the way they learn. New York: Palgrave Macmillan.

Smordal, O. \& J. Gregory. (2003). Personal digital assistants in medical education and practice. Journal of Computer Assisted Learning, 19, 320-29.

Traxler, J. (2009). Learning in a mobile age. International Journal of Mobile and Blended Learning, 1(1), 1-12.

Turner, N (2012). What is mlearning? Retrieved on 20 March 2013 from http://aurionlearning. files.wordpress.com/2012/03/mobile-devices1.jpg

Vosloo, S. (Ed.). (2012). Mobile learning. Paris: United Nations Educational, Scientific and Cultural Organization (UNESCO).

Vavoula, G., Sharples, M., Rudman, P., Meek, J., \& Lonsdale, P. (2009). Myartspace: Design and evaluation of support for learning with multimedia phones between classrooms and museums. Computers \& Education, 53(2), 286-299.

Vogel, B., Spikol, D., Kurti, A., \& Milrad, M. (2010). Integrating mobile, web, and sensory technologies to support inquiry-based science learning. Proceedings of the $6^{\text {th }}$ IEEE International Conference on Wireless, Mobile, and Ubiquitous Technologies in Education (pp.65-72). Los Alamitos, CA: IEEE Computer Society.

Wagner, E. D. (2 005). Enabling mobile learning. EDUCAUSE Review, 40(3), 4 0-53.

Wang, S. L. \& Hwang, G. J. (2012). The role of collective efficacy, cognitive quality, and task cohesion in computer-supported collaborative learning (CSCL). Computers \& Education, 58(2), 679-687.

Correspondence: Hameed Olalekan Bolaji, Ph.D., Department of Science Education, College of Education, Al-Hikmah University, llorin, Nigeria 